\title{
Using mobile technology for cardiovascular disease prevention
}

\section{Diane L. Carroll*}

Massachusetts General Hospital, Boston, United States of America
RECEIVED:

September 27, 2016

ACCEPTED:

October 10, 2016

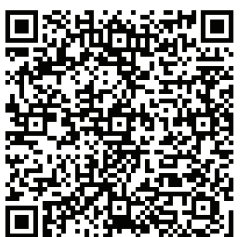

KEYWORDS: cardiovascular disease prevention, mobile technology.

CITATION: Cardiol Croat. 2016;11(10-11):587. | DOI: http://dx.doi.org/10.15836/ccar2016.587

*ADDRESS FOR CORRESPONDENCE: Diane L. Carroll,125 Nashua Street, Suite 763 Boston MA, United States of America. / Phone: +617-724-3494 / E-mail: dcarol3@mgh.harvard.edu ORCID: Diane L. Carroll, http://orcid.org/0000-0002-9415-8065

IIIIIIIIIIIIIIIIIIIIIIIIIIIIIIIIIIIIIIIIIIIIIIIIIIIIIIIIIIIIIIIIIIIIIIIIIIIIIIIIIIIIIIIIIIIIIIIIIIIIIIIIIIIIIIIIIIII

Cardiovascular Disease (CVD) is the leading cause of mortality in Croatia ${ }^{1}$ with $80 \%$ of these deaths potentially preventable with reductions in CVD risk factors. The performance of healthful behaviors related to CVD risk such as smoking cessation, weight and blood pressure management, have become important facets of disease prevention.

Mobile technology (mHealth), the use of smartphones and wearable devices, hold great promise to improve health and reduce CVD. The purpose of this presentation is to review the current literature on mHealth tools available to the consumer for smoking cessation, weight and blood pressure management, as these are the most prominent CVD risks in Croatia. ${ }^{2}$

Studies that were reviewed for smoking cessation, weight management, and blood pressure management. The current literature supports the promise that the use of mHealth tools for short-term weight management, smoking cessation and blood pressure management is achievable. mHealth tools have the ability to 'extend' current face-to-face consultation and education for CVD risk behavior change. These studies tested a variety of mHealth tools but there is little data on the evaluation of tool effectiveness. Future research is needed to produce the evidence of the great potential of mobile technology

1. Kralj V, Brkić Biloš I, Ćorić T, Silobrčić Radić M, Šekerija M. Chronic Noncommunicable Diseases - Burden of Disease in the Population of Croatia. Cardiol Croat. 2015;10(7-8):167-175. DOI: http://dx.doi.org/10.15836/ccar.2015.167

2. Ivanusa M. Milicić D, Bozikov J, Ivanusa Z. [Risk factors as prognostic factors of hospital mortality in patients with acute myocardial infarction]. Acta Med Croatica. 2007;61(3):307-13. PubMed: https://www.ncbi.nlm.nih.gov/pubmed/17629107 